\title{
LINGUA E ESCRITURA NA COMPOSTELA DO SÉCULO XV
}

\author{
Por \\ MERCEDES ALONSO PEQUENO \\ MERCEDES VÁZQUEZ BERTOMEU
}

\section{RESUMEN}

La sociedad bajomedieval gallega es básicamente diglósica, superponiéndose al gallego el latín y el castellano empleado por ciertas autoridades y grupos culturales y religiosos; a estas lenguas es preciso añadir en ciertas zonas y entornos el portugués ( $\mathrm{o}$, al menos, la variante del gallegoportugués empleada al sur del río Miño). Tomando como ejemplo el archivo de la catedral de Santiago donde se elaboraron y utilizaron escritos en todos estos idiomas, se estudia brevemente la posible relación entre la lengua documental y el tipo de escritura.

\begin{abstract}
Late medieval Galicia is basically a diglossic society where Galician is the commonly used idiom and Latin and Spanish are implemented by some authorities and cultural and religious persons and institutions; Portuguese (or the southern Galegoportugues spoken and writen in Portugal) should be added to them in certain regions and environments. The possible connection between language and paleographical variants is briefly studied, taking as an example Santiago de Compostela cathedral archives, where writings were made and used in all these four languages.
\end{abstract}

«CUADERNOS DE ESTUDIOS GALLEGOS», Tomo XLVIII, Fascículo 114, Santiago 2001. 


\section{INTRODUCCIÓN}

Dous séculos antes de que Gutemberg desencadeara a máis grande revolución na elaboración e reproducción de textos, o galego -no seu uso escrito- veu substituír ó latín como lingua documental predominante na Terra de Santiago, igual que o fixera en toda a Galicia medieval.

Os primeiros textos documentais íntegros aparecen neste territorio no século XIV ${ }^{1}$ (tardiamente se se compara co precoz desenvolvemento da literatura lírica) e os últimos rexístranse -anque xa como testemuño excepcional- nos anos centrais do século $\mathrm{XVI}^{2}$.

Os notarios empregan a lingua dos seus clientes á hora de redactar contratos e esta, obviamente, non lles pode ser allea. Así, dada a situación do galego como lingua única do territorio, a gran maioría dos textos atoparémolos na nosa lingua, que constitúe o vehículo de comunicación de tódolos sectores sociais.

Sen embargo, esta situación, na que o galego se está a desenvolver como un sistema lingüístico normal, e na que vai acurtando posicións fronte ó latín, é brevísima, porque o proceso de castelanización lingüística e cultural de Galicia dará comezo demasiado pronto.

$\mathrm{O}$ avance do século XV marca unha nova disposición no panorama galego coa forte presencia do castelán, que abre unha fenda na escrituración en galego. A colaboración dunha marfalla de feitos políticos, sociais e económicos é condicionante decisiva á hora de que estoutra lingua romance se expanda cun éxito asoballante nos rexistros escritos do territorio compostelán.

A comparecencia do castelán non pasara de ser pura anécdota ata entón, pero agora, co amparo que o poder lle presta, incorporará un gran factor de desequilibrio á relación existente entre o latín (lingua de alta cultura reservada a usos moi formais) e o galego (a lingua documental).

\footnotetext{
${ }^{1} \mathrm{O}$ conxunto de textos nacidos no ámbito capitular compostelán datan dos primeiros anos do séc. XIV, aparecen con retraso respecto a outras institucións que xa deixaran a redacción latina medio século antes.

${ }^{2}$ MONTEAGUDO ROMERO, H.: «Aspectos sociolingüísticos do uso escrito do galego, o castelán e o latín na Galicia tardomedieval (ss XIII-XV)» en Estudios galegos en homenaxe ó Profesor Giuseppe Tavani. Santiago, 1994, pp. 169-183.
} 
Xungido a esta forzada diversidade idiomática, dáse un fenómeno de interese: a existencia de varios repertorios gráficos segundo a lingua que se empregue. Así, o GALEGO emprega uns tipos escritóricos propios fronte ós utilizados para a escrituración doutros códigos lingüísticos. A circunstancia de que na Compostela medieval se traballe sobre o legado escriturario común, ata chegar a consecución dun sistema independente que se recoñece como propio, fainos pensar en que puido ter nacido como feito diferencial, primeiro fronte ó latín, e despois fronte ó castelán, que estaba a invandir o seu espacio vital.

Esta variedade de repertorios gráficos preséntase nunha zona relativamente pequena: a Terra de Santiago, e nun ámbito, o estudiado por nós, aínda máis restrinxido: o capitular. E resulta máis interesante se temos en conta que este multigrafismo non é orixinal do caso compostelano ${ }^{3}$.

$\mathrm{O}$ mundo da escrituración ten neste período unha grande importancia individualizadora, xa que tamaño, forma e tipo de letra fúndense nunha unidade coa lingua, construíndo, se se nos permite chamarlle así, un macrosigno que adquiriría neste contexto o significado de 'romance galego'.

A singularidade do modelo escritórico galego, como xa o fixera respecto ó latín, mantívose a pesar da forte penetración do castelán, e só se abandona xunto co uso escrito da nosa lingua. Este abandono que traerá tan graves consecuencias para o galego, deuse no inoportuno momento en que ía aparecer o xenial invento que tantas bondades trouxo consigo, e das que a lingua galega non poderá disfrutar, salvo raras excepcións ata 0 século XIX.

Hoxe, e isto é para todos evidente, non existe ningunha relación entre o modelo escritórico e a lingua da que se fai uso no texto. A pesar de que a escritura impresa estivo fortemente relacionada coa escritura manual nos primeiros tempos, tendeuse cada vez máis a universalización dos tipos.

\footnotetext{
${ }^{3}$ CARMONA, S.: Antropología de la escritura, Barcelona, 1994, p. 101; Petrucci, A.: «Funzione della scrittura e terminologia paleografica» en Paleographica, diplomatica et archivistica. Studi in Onore di G. Batelli. Roma, 1979: p. 10 ; Petrucci, A.: La scrittura di Francesco Petrarca. Cittá del Vaticano, 1967; p. 71.
} 


\section{O PROCESO DIGLÓSICO NA TERRA DE SANTIAGO}

Anterior á penetración do castelán, a situación que se nos presenta non difire daquela na que se atopan as demais linguas romances peninsulares: dáse a coexistencia do galego para usos coloquiais xunto ó latín formal para usos administrativos, literarios, etc. O romance vai ocupando gradualmente os usos da lingua hexemónica nunha cadea ascendente que podemos representar do seguinte modo: usos coloquiais $\rightarrow$ poesía $\rightarrow$ prosa xurídica $\rightarrow$ prosa administrativa.

A medida que o romance gana terreo no uso dos distintos niveis tamén conquista un certo grao de elaboración, intelectualízase debido ás novas funcións que ten que ir cumprindo. Neste sentido adquiren unha importancia crucial os escribáns que serán os encargados de fixa-la lingua máis ou menos conscientemente.

No ámbito capitular compostelán, e quizais noutros cabidos galegos, os textos emanan dun grupo no que os seus membros posúen unha bagaxe cultural media relativamente alta, alfabetizados e versados en latín. Os seus notarios son, con frecuencia, membros da comunidade e, cando non, clérigos que posiblemente se formaron na escola catedralicia. Polo tanto, a lingua latina permanece de modo xeral como referencia á hora de escribir en romance.

A repercusión deste feito ponse de manifesto ó botar unha ollada ás actas capitulares. Permítennos percibir unha lingua escrita moi uniforme, tanto na representación dos sons, como na ortografía e separación das palabras. En definitiva, obsérvanse menos vacilacións e indecisións incluso nas anotacións marxinais. A dificultade non é pequena se temos en conta que o romance presenta numerosos sons que non tiñan correspondencia en latín, o cal obrigaba ó emprego das letras latinas con valores fónicos distintos ós que orixinalmente posuían e á creación de novos signos gráficos ${ }^{4}$.

Hai un certo grao de reflexión e experimentación coa lingua, unha intervención semiconsciente na procura do rexistro máis axustado, así como un tímido intento de codificación lingüística pola vía da compara-

${ }^{4}$ MONTEAGUDO ROMERO, H.: «Aspectos sociolingüísticos do uso do galego, castelán e latín na Idade Media en Galicia» en Revista de Administración Galega, 1, 1985, pp. 85-108. 
ción con aquela na que están alfabetizados e coñecen ben (o latín), á procura dunha variedade rica, culta e tecnicamente máis apta.

$\mathrm{E}$, se ben o reino de Galicia non ten unha corte que actúe como centro, Santiago, constituído na práctica en cabeza do reino galego polo gran poder e autonomía do que é dono o seu prelado, posuiría tódalas características para poder ser considerado o verdadeiro núcleo unificador e xerador dun estándar culto, que ve tronzada a súa natural evolución coa irrupción do castelán, e que, pola contra, irase converter nun importantísimo foco de expansión da lingua foránea.

$\mathrm{O}$ proceso castelanizador encarréirase a mediados do século XIV despois dos conflictos producidos pola sucesión ó trono da coroa de Castela, que abrangue o antigo reino de Galicia, e que ían provocar a infiltración dos primeiros continxentes de elementos casteláns, e, con eles, o idioma ${ }^{5}$. A gran nobreza galega apoiou a causa do perdedor don Pedro I. A victoria por parte de don Enrique de Trastámara trouxo como consecuencia un importante cambio social e o ascenso da nobreza de segundo rango a posicións de primeira fila. Gran parte do persoal galego que ocupaba postos na administración foi substituído por casteláns. Aínda que na Idade Media existía gran permeabilidade sobre todas nas clases altas no que atinxe a ocupar postos clave na administración ou na Igrexa por xente vida de fóra -estas xentes estranxeiras eran asimiladas con rapidez- este novo grupo non vén co talante de ser asimilado e conservará a súa lingua de orixe . $^{6}$.

A preeminencia do castelán sobre as outras variedades lingüísticas dos reinos de Castela e León viña de bastante atrás (mediados do século XIII) e a estas alturas era a lingua oficial de facto no reino?

Nos primeiros momentos a situación que se nos presenta en Santiago é a dun bloque social relacionado coa administración e coa aristocracia, que segundo a súa orixe emprega nos seus usos falado e escrito dúas linguas intercomprensibles. Noutras palabras, dáse un bilingüismo pasivo. A rixidez dunha sociedade como a do medievo supón a existencia do

\footnotetext{
${ }^{5}$ CARBAllo CALERO, R.: «A fortuna histórica do galego» en Problemática das línguas sen normalizar situación do galego e alternativas, IGSP, 1983, pp. 107-128.

${ }^{6}$ Vid. nota 4.

${ }^{7}$ MONTEAGUDO ROMERO, H.: «A lingua galega no século XVI» en Frai Antonio de Guevara e a cultura do Renacemento en Galicia, Lugo, 1993, pp. 25-38.
} 
castelán neste ámbito exclusivamente, e nestas circunstancias podería pensarse que se ía manter estable durante moito tempo.

Non obstante, as castes dominantes galegas vense obrigadas a relacionarse coa cúpula nobiliar foránea, e desde o momento en que, para este trato, se dá o abandono do galego en favor do castelán, comezan a actuar os mecanismos subxectivos que levan a erixir unha lingua en símbolo dun determinado estatus.

O bilingüismo activo no máis alto da pirámide social inaugura a primeira fase da asimilación, nun principio selectiva, que xa se adiviñaba cando este núcleo se instalou en Galicia con todo o seu séquito estranxeiro, constituíndo un foco diglósico estraño e non asimilado ${ }^{8}$.

A diglosia ${ }^{9}$ é a coexistencia conflictiva nunha comunidade de dous códigos lingüísticos, definidos xerarquicamente como lingua dominante A e dominada B, segundo a distribución entre os diferentes grupos sociais, e o seu uso condicionado pola función que nesa comunidade se lle ten asignada a cada lingua

Por outra parte, a proximidade lingüística de ámbolos dous romances determinará en gran medida a amplitude dos fenómenos de interferencia lingüística. Este grao de parentesco vai ser un factor coadxuvante na futura identificación do galego como variedade baixa do castelán, que se recoñecerá como teito lingüístico ${ }^{10}$ ou variedade alta da nosa lingua, e como consecuencia suporá un grave crebanto na depuración dun estándar culto do idioma cuberto ${ }^{11}$.

\footnotetext{
${ }^{8}$ CHACÓN, R. citado en MONTEAGUDO R.,H.: Aspectos sociolingüísticos do uso do galego, castelán e latín

${ }^{9} \mathrm{O}$ concepto de diglosia en Sociolingüística débese a Charles Ferguson (1959) é que despois Joshua Fishman lle daría un sentido máis amplo; en España foi introducido por Rafael LL. Ninyoles que o define en oposición a bilingüismo tendo este un carácter individual, de uso non condicionado e non conflictivo de dúas linguas distintas. Vid. MONTEAGUDO, H.: «Entrevista con Rafael LL. Ninyoles» en Grial 107, 1990, pp. 359-369.

${ }^{10}$ Os conceptos de teito lingüistico e idioma cuberto forman parte da formulación de Žarko Muljačić e que os autores Fernández Salgado e Monteagudo Romero poñen en relación co concepto de diglosia en Fernández Salgado, B. / MONTEAGUDO ROMERO, H.: «Do galego literario ó galego común. O proceso de estandardización na época contemporánea» en Estudios de sociolingüística galega, Vigo, 1995, pp. 99-176.

${ }^{11}$ Vid. nota ${ }^{\circ} 10$.
} 
A estes factores sociais e políticos que precipitaron o ascenso do castelán no seo da sociedade galega, e que fixeron perder a consistencia interna que lle concedía a unidade lingüística e a gran autonomía de que disfrutaba, hai que engadir o forte clima de violencia social e as guerras irmandiñas de 1431 e 1467, e a adopción dunha posición política dubitativa, e en ocasións equivocada, por parte da debilitada nobreza galega ó apoiar á que vai sela perdedora, Juana «la Beltraneja», na loita polo trono de Castela.

A forte política centralizadora dos Reis Católicos ía constrinxír ata a fin o estado relativo de autonomía existente en Santiago, que atopará o seu máis firme valedor por motivacións persoais no arcebispo Fonseca, e que sitúa o centro do poder fóra de Galicia a partir de $1474^{12}$.

$\mathrm{Na}$ Terra de Santiago ten suma importancia que un cargo tan cobizado como o arcebispado fora moi pronto ocupado pola nobreza castelá. Desde os primeiros anos do $\mathrm{XV}$, o arcebispado compostelán gozaba de rendas moi elevadas, e ás funcións eclesiásticas uníanselle outras de tipo político de alto rango. Case se pode falar dun vicerreinado. Na década dos 60 ocupa o posto a dinastía dos Fonseca, ata o segundo tercio do XVI, e aínda que se pode pensar nunha relativa galeguización: Afonso II de Fonseca diríxese ó Cabido en galego repetidas ocasións, mentres que o seu fillo Afonso III de Fonseca faino puntualmente'e no relativo a cousas de menor importancia ${ }^{13}$. O que existe, na nosa opinión, é unha «galeguización» de comportamentos, porque os Fonseca participan plenamente na dinámica sociopolítica galega pero son personaxes claramente vinculados a Castela (Salamanca). Non hai máis que pensar na introducción de cóengos próximos a eles e case todos casteláns, e esta ligazón co poder central fomentada polos Fonseca puso fin a un estado de semiindependencia que ata entón si existira. Neste contexto, unha lingua administrativa propia deixa de ter sentido no momento en que hai que falar cunha administración que posúe outra distinta.

A situación desestabilízase completamente dende o momento en que resulta imprescindible o dominio da lingua castelá para a promoción so-

\footnotetext{
${ }^{12}$ Antes da chegada ó trono en 1474 dos Reis Católicos as relacións con Castela non deberon ser moi fortes.

${ }^{13}$ MONTEAGUDO, H.: «Aspectos sociolingüísticos do uso do galego, castelán e latín na Idade Media en Galicia» en Estudios galegos en homenaxe ó Profesor Guiseppe Tavani. Santiago, 1994, pp. 169-183.
} 
cial. Comeza a experimentarse unha lenta mobilidade social, a través da carreira burocrática, e a partir de agora é de extrema importancia a instrucción -sobre todo legal-, co cal ganan relevancia os centros de ensino que, como sucedeu co núcleo de poder, estan fóra de Galicia. A Universidade de Santiago fundouse a finais do XV pero non funcionou realmente ata moito despois. Neste mesmo momento, o Estudio de Salamanca, verdadeira universidade da arquidiócese compostelá, deixa de selo sen que o Estudio de Santiago chegue a substituíla.

A reestructuración lingüística que empezara no máis alto da pirámide social ábrese cara abaixo, traballando os mecanismos de substitución nun sentido horizontal desde o momento en que sectores da nobreza baixa e da fidalguía cidadá van uníndose ás camadas dominantes.

Se temos en conta que na segunda metade do XVI o bilingüismo diglósico está fondamente asentado en Galicia -evidencia que se nos mostra pola case inexistencia de manifestacións escritas na nosa lingua ata o XIX-e pensamos na súa relación co latín, sendo este o vehículo de certos modos específicos de comunicación e lingua da Igrexa, a nosa lingua experimenta o proceso diglósico común a tódalas linguas romances, para despois principiar un longuísimo período no que os elementos activos en conflicto van se-los romances galego e castelán. Esta conexión establecida entre ambos vén marcada polas transformacións políticas, sociais e económicas que convulsionan a sociedade medieval.

Con este estado de cousas, no continuo proceso diglósico do galego ${ }^{14}$ felizmente interrumpido pola etapa de normalidade do século XIV ó XV, cremos ver, na especial forma de escrituración compostelá, un fío conectivo do proceso, que sería utilizada como marca distintiva respecto ás outras linguas, e que logra o seu maior grao de perfección no século XV.

Por outra parte, era a etapa en que o galego afrontaba un camiño diverxente do seguido polo portugués e que, dende as orixes ó século XIV, fixeran xuntos ${ }^{15}$. Período que poderíamos considerar un dos pasos na

\footnotetext{
${ }^{14}$ Cáccamo, C.: «Cara unha caracterización da diglósia galega: história e presente dunha dominación lingüística», Grial, 79, 1983.

${ }^{15}$ Santamarina, A.: «Norma e estándar» en Estudios de sociolingüística galega, Vigo, 1995, pp. 53-98.
} 
elaboración ${ }^{16}$ lingüística do galego, e que renace no XIX sen que exista para os seus artífices o máis mínimo coñecemento dos logros do pasado.

\section{O MODELO GRÁFICO GALEGO}

O conxunto de textos outorgados no ámbito capitular compostelán son unha fonte de gran valor, xa que constitúen unha serie ininterrumpida de escritos practicamente na súa totalidade en romance. Estes datan dos primeiros decenios do séc. XIV, con certo retraso respecto a outras institucións que medio século antes abandonaran a redacción latina, e incumben a case todo o territorio da diócese compostelá.

$\mathrm{O}$ enraizamento do multigrafismo na Terra de Santiago e en Galicia aínda está por valorar, pero o que si é evidente é que os escritores -polo menos os capitulares- identifican formas que habitualmente se califican de rústicas cun sistema gráfico propio da lingua local, que se diferencia claramente do que empregan cando compoñen ou trasladan textos en língua latina, ou noutros romances.

Sen dúbida, a escritura en galego é a que presenta maior variedade de formas, xa que é a máis utilizada e é a que dominan en toda a súa amplitude os escritores.

Aínda que non é o noso propósito abordar cuestións paleográficas, si nos parece interesante introduci-las características máis sobresalientes da escrituración no campo capitular. Os tipos caligráficos utilizados concordan, en liñas xerais, co estilo propio das escrituras do século XV. Existen, sen embargo, dúas circunstancias que merecen destacarse: por un lado, a dife-

16 Žarko Muljačić establece unha caracterización sociolingüística das variedades lingüísticas románicas (1983), na que revisa o modelo de Heinz Kloss (1958), e na que conceptos como o de distancia (Abstand) e elaboración (Ausbau) fan referencia respectivamente ás características naturais e internas de toda variedade lingüística e ás relacionadas co compoñente artificial ou función social e cultural que na comunidade se lle conceda a cada unha das linguas empregadas. Muljačić organiza arredor da Abstand Galego-Portuguesa os dous Ausbau: galego e portugués que se foron consolidando con diferente fortuna. Por outra parte, o profesor Ž. Muljačić concibe como dinámicos os factores distancia e elaboración que poden cambiar a través de determinados procesos sociolingüísticos. Vid «Do galego literario ó galego común.O proceso de estandardización na época contemporánea» en Estudios de sociolingüistica galega, Vigo, 1995, pp. 99-176. 
rencia existente entre a escritura de documentos públicos que fan efecto fóra da institución e as actas e escritos internos, e que apunta á existencia de escrituras cursivas fortemente personalizadas; e por outro a existencia de catro sistemas gráficos diferenciados, un para cada unha das linguas nas que se escriben documentos: galego, latín, castelán e portugués.

A administración colexiada do cabido fai necesario o rexistro por escrito dos acordos comunitarios e a xustificación das accións persoais. Neste contexto, a escritura adquire un forte valor instrumental na xestión e na toma de decisións. A autoría material destes documentos de uso interno correspóndelles ós coengos, e ás veces ós propios notarios, que empregan unha escritura fortemente personalizada. Cada individuo crea, partindo do modelo gráfico básico, a súa propia variante, de xeito que poden aillarse claramente as distintas autorías. Este proceso é un elemento definidor dun grupo moi acostumado a ler e escribir, é dicir, familiarizado co feito escrito.

Pola contra, nos documentos de carácter público a escritura despersonalízase, dando lugar a un modelo máis uniforme.

A cuestión dos ciclos gráficos na Galicia medieval foi estudiada polo Prof. Lucas Álvarez en varios traballos: a súa conclusión máis evidente é a existencia dun ritmo propio na sucesión dos diversos tipos escritóricos ${ }^{17}$. A este dato hai que engadir outro que é ben coñecido por calquera investigador que consultara documentación galega: a apariencia rústica que presenta a escritura neste territorio.

Esta mesma circunstancia foi posta de manifesto polo mesmo autor, que chega a definir para o período gótico unha letra gótica galega documental. O Prof. Lucas describe para o período gótico, que chega ata a $2^{\mathrm{a}}$ metade do século XIV, unhas características que se seguirán a manter nos ciclos posteriores:

- gusto polo trazo groso.

- deseño descuidado das letras.

${ }^{17}$ LUCAS ÁLVAREZ, M.: «Características paleográficas de la escritura gótica gallega: escritorios notariales compostelanos» en Cuadernos de estudios gallegos, 5, 1950, pp. 53-86; Idem: «Paleografía gallega. Estado de la cuestión» en Anuario de Estudios medievales, 21, 1991, pp. 419-469.

«CUADERNOS DE ESTUDIOS GALLEGOS», Tomo XLVIII, Fascículo 114, Santiago 2001. 
- tendencia á separación dos signos

- preferencia polas formas redondeadas.

A variedade de tipos paleográficos documentais do $\mathrm{XV}$, sempre dentro das características expostas, iníciase con modelos que poderían denominarse precortesáns. A súa aparición dátaa Lucas Álvarez na década dos 40 do século XIV. Algúns escritos dos primeiros anos do XV mostran aínda formas un tanto angulosas, algunhas duplicacións de letras, algunhas curvas e trazos superfluos -signos característicos do período gótico-anque en menor medida que nos anos seguintes.

A escritura cortesá non chega a alcanzar a sofisticación da castelá, pero si o fai nalgúns dos seus elementos nas primeiras décadas do século XV. Nos anos 20 detéctanse signos e elementos que se califican de modo habitual como pertencentes ó sistema de escrituras cortesás, pero que alternarán con outras formas: o $\boldsymbol{a}$ formado por dúas curvas cóncavas unidas pola parte superior e o de lineta, pero tamén deseños máis antigos realizados en dous golpes de pluma; o $\boldsymbol{d}$ uncial aínda que é máis habitual o de trazo recto; o $\boldsymbol{g}$ simple realizado en dous trazos; o $\boldsymbol{p}$ de formas sinxelas; o $\boldsymbol{r}$ redondo pero tamén con forma de martelo; o $\boldsymbol{s}$ en espiral, xunto co de dobre curva e o alto, ademais do que ten un ollo na parte inferior e vai en posición final ou intermedia e marcando un son de difícil definición e adopta forma de 5 ; $0 v$ formado por dúas liñas curvas, a primeira das cales é máis alta e tende a volver sobre os signos anteriores; o $z$ de trazo horizontal prolongado ou caído. Nos anos centrais do século e máis frecuentemente canto máis tardío é o texto, o $\boldsymbol{o}$ precedido dun semicírculo.

As maiúsculas son inda gotizantes, pero cada vez máis soltas e áxiles. Os nexos concrétanse case únicamente nos grupos $c t$, st e sc. O signo abreviativo xeralmente empregado é o guión e o signo $\infty$, que tamén pode significar -eir ou -ar. En xeral téndese cara formas redondeadas e robustas, con caídos e hástiles que saen da liña, pero non dun modo ostentoso.

Progresivamente esta escritura escasamente dinámica ganará velocidade, e con iso, vencerá a inercia dos signos separados e da simplicidade. Esta inclinación alcanza o cénit nas cursivas notariais dos anos 80 e 90 . Neste grupo, as tendencias xerais aprécianse xa desde os anos 20 . A letra é moi rápida e dinámica, sen perder por iso o escaso gusto pola unión de signos dun golpe, a tendencia a diminuír a cadencia e contraste entre hástiles e caídos, que se curvan sobre a liña ou se acurtan. A estructura dos 
signos defórmase para ganar velocidade ó deseñarse nun só trazo as formas envolventes; os signos abreviativos enlazados a outra letra e os nexos multiplícanse orixinando formas novas pero perecedeiras.

Polo contrario, nos códices a escritura permanece fortemente influenciada polos modelos góticos. Son cursivas textuais ou formatas, que eles mesmos denominan letera formada. É unha escritura pesada, na que a verticalidade desapareceu, as letras descompóñense en varios trazos, os nexos redúcense ós grupos $s t$ e $s c$, a tendencia á separación de palabras acentúase, consérvase a duplicación dalgunhas letras e os signos abreviativos redúcense a unha leve marca.

No século $\mathrm{XV}$, a pesar da evolución constatada séguense a manter as mesmas características diferenciais observadas no período gótico: preferencia polo trazo groso, deseño descuidado das letras, tendencia á separación dos signos e gusto polas formas redondeadas. Estes elementos conformarían o modelo gráfico identificado co galego.

En fin, se ben non existe unha creación dun modelo gráfico novo tampouco se trata dunha absorción do sistema imperante no reino castelán. Podería ser unha reinterpretación, unha adaptación de formas novas, máis áxiles e modernas, en función da tradición e da idiosincrasía da lingua propia.

\section{OUTROS REPERTORIOS GRÁFICOS: A DIFERENCIACIÓN}

A existencia posible dun sistema ou modelo de escritura propio dedúcese da presencia na documentación doutros repertorios. O seu emprego está en función da lingua do acto documentado. Esta variedade permite desterrar-alomenos nun primeiro momento- a idea tradicional que atribúe a peculiar apariencia da escritura medieval en romance á impericia e escasa habilidade dos escribas. Non existe dúbida de que en moitos casos esta teoría é ben certa, pero -a luz destas circunstanciasnon pode en ningún caso dárselle un carácter xeral.

\subsection{O latín}

Os textos escritos en latín proceden en xeral da actividade eclesiástica: son sentencias, nomeamentos e, máis raramente, privilexios. Algúns foron redactados e escritos por cregos composteláns, outros son simples 
copias de documentos outorgados noutras institucións, especialmente na curia romana. Os mencionados textos compóñense cun repertorio gráfico que imita ás escrituras curiais pontificias e as súas formas miúdas, estilizadas e elegantes. Esta é unha práctica compartida polos notarios do cabido, cóengos, e os apostólicos ${ }^{18}$, nos cales é difícil atopar un texto latino que non empregue estas variedades de procedencia foránea.

\section{2. $O$ castelán}

O castelán, xa durante o século XV, como é unha lingua sobradamente introducida en Galicia como para que polo menos os notarios e escribáns urbanos a dominen.

Cando se trata de dar forma a documentos en castelán, úsanse preferentemente as formas pertencentes ó modelo cortesán. A pesar de que esta variedade é o referente básico da escritura en galego do momento, as formas son diferentes. O texto énchese de formas curvas e feituras envolventes, con bucles e lazos, nexos e enlaces entre letras e incluso palabras, o conxunto gana en dinamismo, alixeirándose da pesadez $\mathrm{e}$ rixidez das formas galegas ${ }^{19}$. Neste caso si que se aprecia a intención de reproducir coa maior exactitude posible o modelo castelán, sen reelaboración algunha do sistema.

\section{3. $O$ portugués}

Os escasos documentos en portugués, que en realidade son traslados de textos redactados por notarios de além Miño, presentan unha escritura posiblemente moi similar á orixinal e en todo caso, radicalmente diferente ós sistemas que existen no reino castelán e cercana ós repertorios lusos ${ }^{20}$.

${ }^{18}$ Arquivo da Catedral de Santiago (ACS), No 669 A-B, fo 89r-92r (1483), 160r-161r (1517); ACS, Carpeta Documentos Soltos 1, $\mathrm{n}^{\circ}$ 18, 24-1, 26-1, 27; ACS, Carpetas Documentos Soltos 16, $\mathrm{n}^{\circ}$ 12; ACS, Carpeta Documentos Soltos 18, $\mathrm{n}^{\circ}$ 5, 8; ACS, Libro de Posesións e Anexións, $\mathrm{f}^{\circ}$ 258r; ACS, Tumbo de Tenencias 3, $\mathrm{f}^{\circ}$ 291r; ACS, Tumbo E, $\mathrm{f}^{\circ}$ $103 \mathrm{v}, 106 \mathrm{v}, 115 \mathrm{r}-115 \mathrm{v}$.

${ }^{19}$ ACS, No 669 A-B, fo $89 \mathrm{r}-92 \mathrm{r}$ (1483), ACS, Actas Capitulares I, fo 215v-216r, 249r-250v; ACS, Carpeta Documentos Soltos 19, $\mathrm{n}^{\circ}$ 34; ACS, Libro de Constitucións 3, fo $91 \mathrm{v}$.

${ }^{20}$ ACS, Carpeta Documentos Soltos 15, $\mathrm{n}^{\circ} 74$ (1444); ACS, Carpeta Documentos Soltos 19, $\mathrm{n}^{\mathrm{o}} 36$ (inserido), 37; ACS, Tumbo D, fo 29r-30v (1446); ACS, Tumbo E, $\mathrm{f}^{\mathrm{o}}$ $108 \mathrm{r}-110 \mathrm{r}$.

«CUADERNOS DE ESTUDIOS GALLEGOS», Tomo XLVIII, Fascículo 114, Santiago 2001. 
É posible que esta variedade sexa simplemente unha repetición ou copia dos modelos escriturarios foráneos, é dicir, que se limiten a copiar a apariencia do modelo, pero sobre todo no caso latino e portugués certos indicios apuntan a que os notarios coñecen suficientemente estes repertorios. Compóñense con frecuencia escritos en latín, pero non son só documentos estereotipados como as concesións ou títulos de beneficios, senón tamén textos máis narrativos e complexos como as sentencias ou testemuños que requiren do escritor maior habilidade que a de encher un formulario. No caso portugués, ó carecer dos escritos orixinais resulta moi difícil establecer a suficiencia de quen escribe. Sen embargo, nestes traslados desenvólvense sistematicamente certas abreviaturas que, se ben aparecen marcadas no texto do mesmo xeito que en galego, resólvense de modo diferente, como os $\mathbf{- m}$ finais ou algunhas formas verbais e abreviaturas que inclúen os dígrafos $\mathbf{l h}$ e $\mathbf{n h}$ (que normalmente se abrevian). Non obstante, cabe a posibilidade de que xa estiveran así nos orixinais.

\section{CONCLUSIÓNS}

- No período medieval, a lingua galega acadou unha innegable madurez. Segue as mesmas pautas de desenvolvemento das linguas próximas: adaptación das formas gráficas do alfabeto latino ós sons propios ou creación de variedades técnicas para responder ás novas necesidades dos diferentes usos escritos da lingua. $\mathrm{O}$ uso instrumental do galego neste período, que vai dende o século XIV ó XV, supón o asentamento da linguaxe xurídica en Santiago, como pode apreciarse nos documentos da última centuria. Anque se rexistren variedades persoais e zonais, a estructura dos contratos é máis fixa, e a terminoloxía e sintaxe menos dubitativas, debido á práctica adquirida ó longo do tempo.

- Parece existir nos escritores unha clara consciencia do galego como lingua cun sistema gráfico propio e diferenciado. A pesar de que non se trata dun repertorio orixinal, innovador nin de creación propia, senón unha reelaboración do que tamén predominaba no reino de Castela. Este evidente intento diversificador levaríanos a pensar nunha finalidade diferencial que se materializa na fisonomía das letras.

- No territorio da Terra de Santiago tomado como base deste estudio podería existir un centro difusor destes procesos. Só no ambiente ecle- 
siástico compostelán pode concebirse o nacemento e desenvolvemento dunha linguaxe xurídica e eclesiástica en galego que se espalle uniformemente por todo o seu espacio de influencia.

- O emprego dun repertorio gráfico específico para o galego que podería interpretarse como sinal diferencial fronte ó latín primeiro e logo fronte ó castelán, vese perturbado e influído polos usos gráficos deste último a finais do XV e detéctase un paulatino acercamento cara o estilo castelán á vez que os textos se inzan de castelanismos, e que responde á distinta consideración en que se ten a lingua e os antigos tipos gráficos de que esta facía uso. Este fenómeno explicaríase nunha realidade diglósica que se está a padecer nas terras compostelás.

«CUADERNOS DE ESTUDIOS GALLEGOS», Tomo XLVIII, Fascículo 114, Santiago 2001. 